\title{
Diagnosis of cytomegalovirus infection: a review
}

\author{
Deenan Pillay, Paul D Griffiths
}

\section{Introduction}

Cytomegalovirus (CMV) infects between 40 $100 \%$ of adults throughout the world, depending primarily on socio-economic status. However, other relevent factors include the degree and form of sexual activity such that, in the UK, homosexual men have a seroprevalence of $80 \%$ compared with $42 \%$ of sexually active male heterosexuals. ${ }^{1}$ These individuals may present to genitourinary medicine clinics with CMV-related symptoms, most of whom will be infected with HIV.

As a member of the herpes group of viruses, infection with CMV leads to a state of latency with the capacity to reactivate at any time. Primary infection in the immunocompetent is usually asymptomatic but may be associated with a mononucleosis-type illness. Reactivation is of major consequence in those who are immunocompromised in whom it may be associated with retinitis, colitis, pneumonitis or encephalitis, all of which carry significant morbidity. ${ }^{2}$

The availability of effective anti-CMV therapy has heightened the requirement for rapid, sensitive methods of CMV detection, and these will be discussed in detail. By contrast, serological diagnosis of CMV infection (ie antibody determination) depends on a functional immune system and, we believe, plays little role in CMV diagnosis in the immunocompromised individual.

Despite the severe symptomatology associated with CMV, it is important to realise that infection does not equate with disease. Thus, virological evidence of CMV infection must always be interpreted within the clinical context before treatment is considered.

\section{Virus isolation}

The detection of CMV in clinical specimens by growth in conventional cell culture (CCC) remains the "gold standard" against which any new detection system must be compared. Human CMV is highly species specific and thus will only grow in human fibroblasts, a cell line commonly employed in clinical virology laboratories. ${ }^{3}$ The characteristic CMV cytopathic effect (CPE) consists of small round or elongated foci of rounded, enlarged refractile cells (fig 1), which usually develop 2-3 weeks following inoculation, but may take up to 6 weeks. The clinical specimens most commonly inoculated are urine, saliva (or throat swab taken into viral transport medium) and the "buffy coat" component of whole blood which has been taken into preservative-free heparin. However, CMV can be isolated from a wide range of tissues, and biopsy samples taken into viral transport medium and subsequently homogenised prior to inoculation are especially valuable for the diagnosis of invasive disease. Rapid transport of samples from ward to laboratory is essential since CMV is a labile virus. If this is not possible the sample should be stored at $4^{\circ} \mathrm{C}$ and never frozen.

\section{Rapid culture systems}

The major disadvantage of CCC relates to the time lapse between inoculation of clinical specimen and appearance of the characteristic CPE. In addition, this time period allows for potential contamination of cultures, and the overgrowth of coexisting viruses which may act to hide CMV. Attempts to develop more rapid methods have been stimulated by the development of monoclonal antibodies directed against CMV proteins. Following viral infection of a permissive cell, CMV immediate early and early proteins are produced within the first 8 hours, with viral DNA replication occurring up to 24 hours later, followed by late protein synthesis. ${ }^{2}$ The ability to detect early proteins by fluorescent tagged monoclonal antibodies was therefore utilised by workers in our laboratory to develop a rapid diagnostic assay. This technique, DEAFF (detection of early antigen fluorescent foci) is simple to perform and can be undertaken on a routine, daily basis. ${ }^{4}$ Clinical specimens are inoculated into fibroblast monolayers on eight-well slides. Following 16 hours incubation the cells are acetone fixed, and CMV protein detected by an immediate early protein monoclonal antibody, to which a fluorescence-conjugated antispecies antibody can be bound. It is essential that this latter antibody is non-human, in order to avoid binding to cellular $\mathrm{Fc}$ receptors which are induced by CMV infection. A positive result can be detected by bright nuclear staining under the fluorescent microscope (fig 2). A comparison of this technique with conventional cell culture (CCC) has shown the sensitivity of DEAFF to be $78 \%$ compared with $76 \%$ for CCC, taking a positive by either method as a true positive. It is likely that DEAF does not detect very low titres of virus in clinical samples, which take a longer than average time to be detected in CCC. ${ }^{5}$ On the other hand it is intriguing to speculate whether DEAFF, but not CCC, detects virus in the presence of antiviral drugs, since CMV early antigen production is not dependent on prior viral genome replication, a target of these drugs. Conversely, drug carry over from a clinical specimen would inhibit viral growth in CCC such that no CPE would be observed.

A potential problem associated with any
Address for correspondence: Dr Deenan Pillay.

Accepted for publicatio 19 November 1991 
Fig 1 The typical cytopathic effect of cytomegalovirus seen in a human embryo lung fibroblast monolayer.
Fig 2 Cytomegalovirus infection diagnosed by detection of early antigen fluorescent foci (DEAFF).
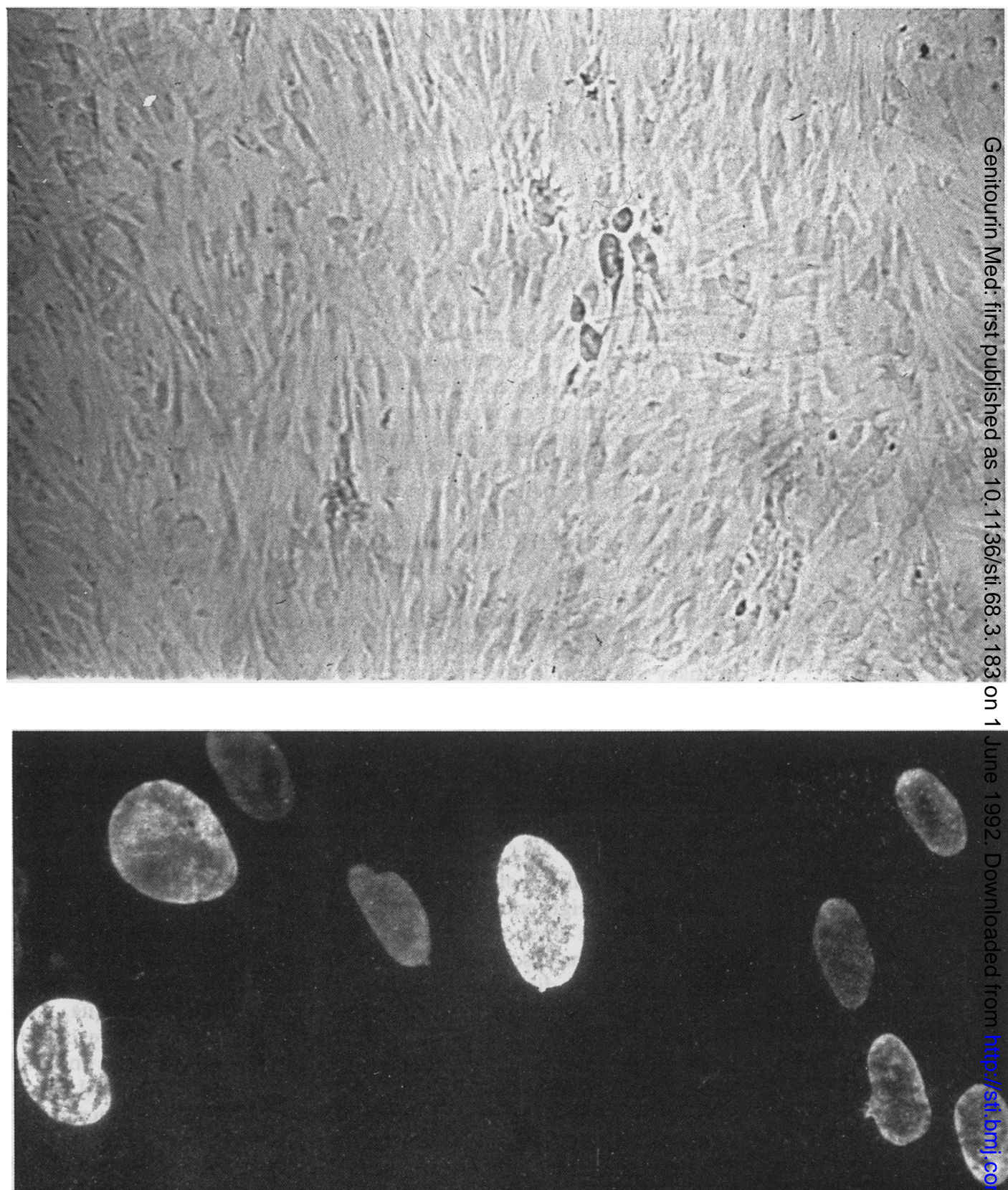

assay system relying on monoclonal antibodies is that of antigenic variation, such that the respective antigen in a variety of CMV strains may not be detected. Until a single monoclonal antibody can be produced which is shown to react with a group-specific antigen, it is generally assumed that the use of a pool of monoclonal antibodies in this technique is preferable.

A similar technique to the DEAFF test has been described in which inoculation of clinical specimen and the subsequent fluorescent staining are carried out on a cover slip, held either within a shell vial ${ }^{6}$ or on a slide support. ${ }^{7}$ While this method may be more labour intensive than DEAFF, it does allow for centrifugation of the inoculated cell monolayer which can increas the sensitivity of viral detection. "Centrifuga enhancement" is a relatively specific proper of CMV cultures, and increase in infectivity is greatest at low $(1000 \mathrm{~g})$ rather than high speeg centrifugation. The precise mechanism of cert. trifugal enhancement remains unclear. ${ }^{9}$

\section{Antigen detection}

Direct immunofluorescent techniques can also be used on fixed tissue sections, or cytospin 
preparations of cell suspensions in order to detect CMV antigens. ${ }^{10-13}$ The latter method has been evaluated for bronchoalveolar lavage material, the main advantage over conventional cell culture and DEAFF being that of speed of processing. However, the sensitivity for CMV detection from such fluid is low and this method alone cannot therefore be recommended for diagnosis of lung infection from lavage fluid. ${ }^{11}$ On the other hand, immunofluorescence on frozen sections as well as on formalin fixed and deparaffinised tissue sections, such as liver, brain or lung may be an important adjunct to a virological or histological diagnosis.

Immunofluorescent detection of CMV early antigens in blood polymorphonuclear leucocytes (PMNC) has been used to assess viraemia in a wide range of immunocompromised patients. This requires the preparation of cytocentrifuged slides to contain around 50,000 cells per preparation. The sensitivity of this technique appears to be at least equivalent to rapid culture techniques with the advantage that results can be obtained within 5 hours of sampling. ${ }^{14}{ }^{15} \mathrm{~A}$ further benefit is that antigen staining cells can be counted relative to total fixed PMNC, allowing a semi-quantitative assessment of CMV viraemia. ${ }^{16}$ As discussed above, the specificity of the monoclonal antibody used in any immuno-assay is important, and the precise antigen detected in many of the published studies of this technique has yet to be fully clarified, as it appears that some recognise an early protein processed by leucocytes rather than the major immediate early protein.

The above methods relate to detection of cellular CMV since the virus is very cellassociated, and therefore all involve some preparative work on the clinical specimen. However, cell-free CMV is excreted in large amounts in urine and some groups have attempted to develop simple enzyme immunoassays for urinary detection of virus. This has proved to be problematic, one reason being that such virus is coated the host protein B2microglobulin. ${ }^{17} \mathrm{~A}$ consequence of this would be that antigenic determinants are masked, making recognition by antibody difficult. We are currently investigating methods by which antibodies directed against both CMV antigens and B2-microglobulin could be incorporated into a simple assay system for urinary CMV detection.

\section{Histology and cytology}

Histological diagnosis of $\mathrm{CMV}$ infection in fixed tissue sections is usually made by detection of intranuclear inclusions, surrounded by an "owl's eye" halo." Although such a procedure lacks sensitivity, it is one of the ways of diagnosing invasive CMV disease. If CMV infection is suspected, immunocytochemical detection of viral antigens should also be undertaken on these sections. Inclusion bearing cells can also be found in saliva, urine, bronchoalveolar lavage fluid and touch preparations of CMV infected tissues. $^{18}$
However, sensitivity of cytological diagnosis is similar to that for histological diagnosis.

\section{DNA detection}

Viral genome detection has, until recently, depended on the availability of specific CMV oligonucleotide probes which do not cross react with non viral gene sequences. This is of particular relevance to the detection of $\mathrm{CMV}$ DNA since several regions of the CMV genome contain sequences of homology with the human genome,${ }^{19}$ and therefore a prerequisite for the use of this methodology is the use of probes unique to CMV. These probes are usually radioactively labelled to allow detection of target sequences by autoradiography. At present few diagnostic laboratories have facilities for nucleic acid detection as a routine service; however, this situation is likely to change in the next few years, especially with the development of non-isotopic methods for genome detection. ${ }^{20}$

In situ hybridisation has been shown to detect CMV DNA or RNA in tissue specimen sections, even in cells that do not appear to be infected by standard histological criteria. ${ }^{21} 22$ However, in comparison with conventional and rapid cell culture, it was shown to be the least sensitive for the detection of CMV DNA in bronchoalveolar lavage samples. ${ }^{23}$ The dot-blot method of hybridisation, requiring an initial extraction of nucleic acid from clinical samples, has been reported to be a more reliable method for CMV detection, especially from urine..$^{2425}$

The above techniques have now been superseded by the polymerase chain reaction (PCR). This is a method for in vitro amplification of specific gene sequences prior to detection. It requires the presence of specific primers complementary to DNA sequences on either side of a target CMV DNA segment of known size. By repeated cycles of heating and cooling, in the presence of a heat stable DNA polymerase, a single gene copy may be amplified up to one million fold. This may subsequently be detected following electrophoresis of the PCR mixture in the presence of a nucleic acid stain, since the gene is of known molecular size; however, confirmation may be made by subsequent hybridisation with a labelled oligonucleotide probe. ${ }^{20}$ It follows that the major benefit of PCR is its high sensitivity for CMV detection. Conversely, PCR is highly susceptible to contamination by extraneous viral material, a problem of particular concern to a diagnostic virology laboratory in which CMV is commonly grown to a high titre. The improved sensitivity of PCR compared to other methods of CMV diagnosis has been documented for viral detection in blood and urine samples, in HIV infected as well as other immunocompromised patients. ${ }^{26-29}$ However, a possible limitation of this high degree of sensitivity is based on the knowledge that normal viral replication gives rise to a large proportion of defective viral particles, unable to take part in further productive infection. It is likely that such genomes would be detected by a PCR technique, despite the fact that their presence 
does not necessarily denote active viral infection, nor constitute evidence of disease. Formal assessment of prognostic value of any given PCR method is therefore mandatory. Alternatively, a discriminative reporting of PCR results may be of more use than merely a positive or negative result. Of interest is the recent development of a quantitative PCR method for detection of CMV in clinical samples ${ }^{30}$ which has been used to show that a high CMV genome copy number in urine is more likely to be associated with CMV disease than a low copy number (personal communication; JC Fox, PD Griffiths and VE Emery).

\section{Serology}

Serological diagnosis of viral infection normally depends on the detection of a seroconversion, a four fold or greater increase in titre of antibody, or the presence of specific circulating IgM, and sensitive methods are now widely available for the detection of CMV IgG and IgM. The immunocompromised patient, however, is characterised by an inability to mount normal immune responses, especially to a reactivation of latent infection, as is often the case with $\mathrm{CMV} .^{3031}$ The disadvantages of serological methodology over virus detection are therefore lack of sensitivity, and delay in diagnosis, since the serological changes which do occur in response to infection are often late in onset. ${ }^{32}$ The measurement of local specific antibody production, such as has been carried out in bronchoalveolar lavage fluid from transplant recipients with CMV pneumonitis, has also been shown to be of no diagnostic benefit. ${ }^{32}$ In HIV infected individuals the most useful role of serology is the determination of $\mathrm{CMV}$ IgG status, which allows categorisation of patients into those who are liable to $\mathrm{CMV}$ reactivation and those who are not.

\section{Diagnosis of CMV disease}

As discussed above CMV infection does not equate with CMV disease. A diagnosis of disease depends on a combination of virological and clinical data together with an assessment of the individual's risk factors, such as the degree of this immunocompromise. Close cooperation between the clinician and virologist is therefore essential. Some important aspects in the diagnosis of CMV related disease in HIV infected individuals are discussed below.

\section{Gastrointestinal disease}

Although almost all areas of the gastrointestinal tract may be infected with CMV, the most common manifestation is diarrhoea due to CMV colitis. Since many other opportunistic and non-opportunistic infections may present in an identical manner, a biopsy diagnosis is usually required before onset of treatment. The ascending colon has previously been thought to be the most common site of CMV infection ${ }^{33}$; however, other workers have demonstrated rectum and sigmoid colon involvement as well, with a relative sparing of the transverse colon. ${ }^{34}$ It is essential that investigations include a colonscopy with multiple biopsies taken from ascending, transverse and the rectosigmoid region. Symptoms from other areas of the GI tract also require an analysis of relevant biopsy samples for a diagnosis of CMV infection.

Central nervous system disease

Encephalitis and myelitis have been attributed to CMV infection. ${ }^{35}{ }^{36}$ However, although histological involvement of the brain suggestive of CMV infection frequently is noted in post mortem material from AIDS patients, ${ }^{35}$ and CMV antigens and nucleic acid is detected in nervous tissue, it remains difficult to ascribe disease to $\mathrm{CMV}$ infection. ${ }^{37}$ This problem is compounded by the known neurotropism of $\mathrm{HIV}$ itself. In clinical practice, a brain biopsy is often undesirable, and in those with otherwise unexplained neurological symptoms we suggest the sampling of CSF, whole blood and other peripheral sites for CMV detection which, if positive, may support a clinical diagnosis of CMV disease.

\section{Retinitis}

The diagnosis of retinitis is based solely on ophthalmological examination following the onset of symptoms. ${ }^{38}$ The eyes of AIDS patients must therefore be examined regularly, in order that treatment can be initiated promptly. These individuals often require long term maintenance therapy. Although retinitis is often suffered by those with disseminated CMV disease, the detection of CMV elsewhere should have no bearing on the diagnosis of CMV retinitis.

\section{Pneumonitis}

CMV pneumonitis is a common and severe problem following organ transplantation requiring urgent treatment and is diagnosed by detection of $\mathrm{CMV}$ in bronchoalveolar lavage (BAL) fluid. ${ }^{39}$ In contrast, although $\mathrm{CMV}$ is often isolated from lavage fluid of AIDS patients with respiratory signs and symptoms, either alone or in association with other infectious agents, it rarely causes disease. ${ }^{40}$ It is thought that CMV pneumonitis is mainly mediated by immuno-pathological mechanisms, rather than the viral lytic infection which causes damage in other tissues. ${ }^{41}$ As such, the development of pneumonitis depends to some extent on a functional immune response to CMV. AIDS patients commonly have very low CD4 counts when CMV is detected, and may not be able to mount such a response. We therefore recommend that BAL samples are sent for CMV detection in these patients but that a diagnosis of CMV pneumonitis only be made following the failure of treatment for other suspected opportunistic chest infections, and where the $\mathrm{CD} 4$ count is greater than $100 \times$ $10^{6} / 1^{42}$

\section{Prognostic value of $\mathrm{CMV}$ detection}

The severe nature of CMV infection in transplant recipients has led to attempts to define risk factors for disease. One approach has been for regular surveillance cultures, from multiple 
sites, to be undertaken for CMV detection during the high risk post-transplant period. Such studies have shown that CMV isolated from blood, but not urine or saliva, is associated with an increased risk of subsequent CMV disease. $^{4344} \mathrm{CMV}$ viraemic individuals may then be given pre-emptive therapy prior to onset of symptoms, or be closely observed such that treatment can be initiated early if disease develops. A similar prospective study carried out in 71 AIDS patients showed that $50 \%$ of those with CMV viraemia later developed organ disease compared with $9 \%$ of nonviraemic patients, over a mean follow-up period of 16 months. ${ }^{45}$ Further studies are now required in order to determine if anti-CMV pre-emptive therapy can be allocated to AIDS patients on a similar basis (in those who are CMV viraemic) thereby preventing a major cause of morbidity and mortality in this group of individuals.

\section{Conclusion}

CMV related pathology in AIDS patients is being observed to an increasing extent, both because of the growth of this population, and the fact that they are surviving for a longer period. With the availability of effective anti CMV treatments, rapid methods of CMV diagnosis are required in order that early initiation of such treatment can occur. Conventional cell culture remains the gold standard of diagnosis, however rapid culture techniques, and antigen detection have been shown to be both sensitive and specific and are widely used because of their rapidity. Of the array of methods available for detecting CMV genomes in clinical specimens, the polymerase chain reaction is most likely to find its way into diagnostic use. Its major advantage is sensitivity; however, it is also quick, and need not require the use of radioactivity. A full comparison of PCR with other established methods of CMV diagnosis in a clinical setting is awaited.

In conjunction with sensitive detection systems, another potential development for the future is the introduction of prospective diagnosis, or surveillance for CMV infection in AIDS patients. This would allow for treatment options to be considered prior to the onset of symptomatology, and lead to a further enhancement in the quality of life of these individuals.

1 Berry NJ, MacDonald Burns D, Wannamethee G, et al. Seroepidemiologic studies on the acquisition of antibodies to cytomegalovirus, herpes simplex virus, and human immunodeficiency virus among general hospital patients and those attending a clinic for sexually transmitted diseases. J Med Virol 1988;24:385-93.

2 Griffiths PD. Cytomegalovirus. In: Zuckerman AJ, Banatvala JE, Pattison JR, eds. Principles and Practice of Clinical Virology, 2nd ed. 1990;69-102, London, Wiley.

3 Stagno S, Britt WJ, Pass RF. Cytomegalovirus. In: Schmid NJ, Emmons RW. eds. Diagnostic Procedures for Viral, Rickettsial and Chlamydial Infections, 6th edition 1989;321-78, Washington, American Publich Health Association.

4 Griffiths PD, Panjwani DD, Stirk PR, et al. Rapid diagnosi of cytomegalovirus infection in immunocompromised patients by detection of early antigenic fluorescent foci. Lancet 1984;ii:1242-5.
5 Stork PR, Griffiths PD. Use of monoclonal antibodies for the diagnosis of cytomegalovirus infection by the detection of early antigenic fluorescent foci (DEAFF) in cell culture. J Med Virol 1987;21:329-37.

6 Paya CV, Smith TF, Ludwig J, Hermans PE. Rapid shell vial culture and tissue histology compared with serolog for the rapid diagnosis of cytomegalovirus infection in liver transplantation. Mayo Clin Proc 1989;64:670-5.

7 Thiele GM, Bicak MS, Young A, Kinsey J, White RJ, Purtilo DT. Rapid detection of cytomegalovirus by tissue curtilo DT. Rapid detection of cytomegalovirus by tissue culture, centrifugation, and immunofluorescence with a
monoclonal antibody to an early nuclear antigen. $J$ Virol Methods 1987;16:327-38.

8 Gleaves CA, Smith TF, Shuster EA, Pearson GR. Rapid detection of cytomegalovirus in MRC-5 cells inoculated with urine specimens by using low speed centrifugation and monoclonal antibody to an early antigen. J Clin Microbiol 1984;19:917-9.

9 Hudson JB. Further studies on the mechanism of centrifugal enhancement of cytomegalovirus infectivity. $J$ Virol Methods 1988;19:97-108.

10 Volpi A, Whitley RJ, Ceballos R, Stagno S, Pereira L. Rapid diagnosis of pneumonia due to cytomegalovirus with specific monoclonal antibodies. J Infect Dis specific monoclo

11 Stirk PR Griffiths PD. Comparative sensitivity of three methods for the diagnosis of cytomegalovirus lung infecmethods for the diagnosis of cytomega
tion. J Virol Methods 1988;20:133-42.

12 Bronster O, Makowka L, Jaffe R. et al. Occurrence of cytomegalovirus hepatitis in liver transplant patients. J Med Virol 1988;24:423-34.

13 Wiley CA, Schier RD, Denaro FJ, Nelson JA, Lambert PW Oldstone MBA. Localization of cytomegalovirus protein and genome during fulminant central nervous systemic infection in an AIDS patient. $J$ Neuropathol Exp Neurol 1986;45:127-39.

14 van der $\mathrm{Bij} W$, Torensma $\mathrm{R}$, van Son WJ, et al. Rapid immunodiagnosis of active cytomegalovirus infection by monoclonal antibody staining of blood leucocytes. J Med Virol 1988;25:179-88.

15 van der Bij W, Schirm J, Torensma R, van Son WJ, Tegzess AM, The TH. Comparison between viraemia and AM, The TH. Comparison between viraemia and antigenaemia for detection of cy

16 Van den Berg AP, Klompmaker IJ, Haagsma EB, et al. Antigenaemia in the diagnosis and monitoring of active cytomegalovirus infection after liver transplantation. J Infect Dis. 1991;164:265-70.

17 McKeating JA, Grundy JE, Varghese Z, Griffiths PD. The detection of cytomegalovirus by ELISA in urine samples is inhibited by B2-microglobulin. J Med Virol 1986;18:341-8.

18 Shulman HM, Hackman RC, Sale GE, Meyers JD. Rapid cytological diagnosis of cytomegalovirus interstitial pneumonia on touch imprints from open-lung biopsy. $A m$ pneumonia on touch imprints

19 Emery V, Griffiths PD. Molecular biology of cytomegalovirus. Int J Exp Pathol 1990;71:905-18.

20 Desselberger U, Collingham K. Molecular techniques in the diagnosis of human infectious diseases. Genitourin Med 1990;66:313-23.

21 Myerson D, Hackman RC, Nelson JA, Ward DC, McDougall JK. Widespread presence of histology occul cytomegalovirus. Hum Pathol 1984;15:430-9.

22 Myerson D, Hackman RC, Meyers JD. Diagnosis of cytomegaloviral pneumonia by in situ hybridisation. $J$ In Dis 1984;150:272-7.

23 Gleaves CA, Myerson D, Bowden RA, Hackman RC Meyers JD. Direct detection of cytomegalovirus from bronchoalveolar lavage samples by using a rapid in situ DNA hybridization assay. J Clin Microbiol 1989;27: 2429-32.

24 Chou S, Merigan TC. Rapid detection and quantitation of human CMV in urine through DNA hybridization. $N$ Engl J Med 1983;308:921-5.

25 Musiani M,Zerbini M, Gentilomi G, et al. An amplified do immunoassay for the direct quantitation of adapted and wild strains of human cytomegalovirus. $J$ Virol Methods 1989;24:327-34.

26 Shibata D, Martin WJ, Appleman MD, Causey DM Leedom JM, Arnheim N. Detection of cytomegalovirus DNA in peripheral blood of patients infected with human immunodeficiency virus. J Infect Dis 1988;158:1185-92.

27 Einsele H, Steidle M, Vallbracht A, Saal JG, Ehninger G, Muller CA. Early occurrence of human cytomegalovirus infection after bone marrow transplantation as demonstrated by the polymerase chain reaction technique. Blood strated by the polym

28 Cassol SA, Poon M-C, Pal R, et al. Primer mediated enzymic amplification of cytomegalovirus DNA. J Clin Invest. 1989;83:1109-15.

29 Gerna G, Zipet D, Parea M, et al. Monitoring of human cytomegalovirus infections and ganciclovir treatment in heart transplant recipients by determination of viraemia antigenaemia and DNAemia. J Infect Dis 1991;164: 488-98.

30 Pass RF, Griffiths PD, August AM. Antibody response to cytomegalovirus after renal transplantation: comparison of patients with primary and recurrent infections. $J$ Infect Dis 1983;147:40-6.

31 Marsano L, Perillo RP, Flye MW, et al. Comparison of culture and serology for the diagnosis of cytomegalovirus infection in kidney and liver transplant recipients. $J$ Infect Dis 1990;161:454-61.

32 Milburn HJ, Grundy JE, du Bois RM, Prentice HG, 
Griffiths PD. Is the measurement of virus-specific antibody in the lungs of transplant recipients with cytomegalovirus pneumonitis of diagnostic of prognostic value? J Med Virol 1988;26:197-206.

33 Sutherland DER, Chan FY, Foucar E, Simmons RL, Howard RJ, Najarian JS. The bleeding cecal ulcer in transplant patients. Surgery 1979;86:386-98.

34 Rene E, Marche C, Chevalier T, et al. Cytomegalovirus colitis in patients with acquired immunodeficiency syndrome. Dig Dis Sci 1988;33:741-50.

35 Morgello S, Cho ES, Nielson S, Devinsky O, Petito CK Cytomegalovirus encephalitis in patients with acquir Cytomegalovirus encephalitis in patients immunodeficiency syndrome: an autopsy study of 30 cases and a review of the literure. Cyer T, Dix RD, Katzen C, Davis RL, Schmidley JW. Cytomegalovirus and herpes simplex virus ascending myelitis in a patient with acquired immune deficiency

37 Dix RD, Bredesen DE, Erlich KS, Mills J. Recovery of herpes viruses from cerebrospinal fluid of immunodeficient homosexual men. Ann Neurol 1985;18:611-4. 38 Henderly DE, Jampol LM. Diagnosis and treatment of
cytomegalovirus retinitis. J Acq Imm Def Synd 1991;4(Suppl 1):S6-S10.
39 Rubin RH. Impact of cytomegalovirus infection on organ transplant recipients. Rev Infect Dis 1990;12(Suppl 7): S754-S766.

40 Millar AB, Patou G, Miller RF, et al. Cytomegalovirus in the lungs of patients with AIDS: respiratory pathogen or passenger? Am Rev Respir Dis 1990;141:1474-7.

41 Grundy JE, Shanley JD, Griffiths PD. Is cytomegalovirus pneumonitis in allogeneic transplant recipients an immunopathological condition? Lancet 1987;ii:996-9.

42 Squire SB, Lipman MCI, Bagdades EK, et al Severe cytomegalovirus pneumonititis pneumonitis in HIV infected patients with higher than average CD4 counts. Thorax (in press)

43 Webster A, Prentice HG, Pothecary K, Griffiths PD. The value of routine surveillance cultures for detection of CMV pneumonitis following bone marrow transplantation. Bone Marrow Transplant. (in press).

44 Pillay D, Charman H, Burroughs AK, Smith Griffiths PD. Surveillance for CMV infection in orthotopic liver transplant recipients. Transplantation (in press)

45 Salmon D, Lacassin F, Harzic M, et al. Predictive value of cytomegalovirus viraemia for the occurrence of CMV organ involvement in AIDS. J Med Virol 1990;32:160-3. 